ORIGINAL ARTICLE

\title{
Short-term vasculoprotective effects of imatinib mesylate on intimal hyperplasia of arterial anastomosis: An experimental study using a rabbit model
}

\author{
Kamuran Zeynep Sevim MD1, Ozlem Silistreli MD², Metin Gorgu MD³, Osman Sevim MD4, Bekir Ergur MD
}

KZ Sevim, O Silistreli, M Gorgu, O Sevim, B Ergur. Short-term
vasculoprotective effects of imatinib mesylate on intimal hyperplasia
of arterial anastomosis: An experimental study using a rabbit model. Can J Plast Surg 2012;20(4):223-228.

BACKGROUND: Since the beginning of the 'microvascular era', the success rates of microvascular procedures have increased to more than $90 \%$ in most series. The main reason for failure, however, is the healing of microarterial anastomosis, which is dependent on the status of endothelial cells and affects the rate of arterial thrombosis. In $80 \%$ of arterial thrombosis cases, complications are primarily observed during the first $72 \mathrm{~h}$ after surgery. Healing of arterial anastomosis results in intimal hyperplasia in which myofibroblasts comprise the predominant cell type. Intimal hyperplasia has been described previously as an adaptive process that occurs in response to hemodynamic stress or injuries to the vascular bed. During wound healing, fibroblasts proliferate, migrate and differentiate into myofibroblasts - a process that takes one to three days. Imatinib mesylate (ST1571-Gleevec, Novartis, Germany) is a specific platelet-derived growth factor receptor blocker that has found use as an adjunct to sirolimus in cardiovascular surgery for restenosis. However, its potential utility in preventing arterial thrombosis in microvascular surgery has not been evaluated in routine plastic surgery practice.

METHODS: Twenty-four randomly selected, male, white New Zealand rabbits were divided into six groups (A to $F$ ), and the femoral artery model was used for arterial anastomosis. Following anastomosis, groups A, B and $\mathrm{C}$ received phosphate-buffered saline orogastrically. In groups $\mathrm{D}, \mathrm{E}$ and $\mathrm{F}$, imatinib mesylate was administered via an orogastric tube twice per day at anastomosis, imatinib mesylate was administered for one, three and seven days, and the regression of intimal hyperplasia was recorded.

RESULTS: In groups administered imatinib mesylate (ie, groups D, E and F), intimal hyperplasia decreased by up to $50 \%$, which represented a statistically significant difference. Histological analysis confirmed smooth muscle cell migration from the tunica intima to media on days 3 and 7 in groups $E$ and $\mathrm{F}$.

CONCLUSION: The present study revealed that imatinib mesylate, which was initiated as a prophylactic, systemic pretreatment and continued for seven days, gradually decreased intimal hyperplasia at the anastomosis site.

Key Words: Imatinib mesylate; Intimal hyperplasia; Thrombosis a dose of $10 \mathrm{mg} / \mathrm{kg}$ starting two days before arterial anastomosis. Following

\author{
Les effets vasculoprotecteurs à court terme du \\ mésylate d'imatinib sur l'hyperplasie de l'intima \\ causée par l'anastomose artérielle : une étude \\ expérimentale sur un modèle de lapin
}

\begin{abstract}
HISTORIQUE : Depuis le début de "l'ère microvasculaire ", le taux de réussite des interventions microvasculaires a augmenté pour atteindre plus de $90 \%$ dans la plupart des séries. Cependant, la principale raison des échecs provient de la guérison de l'anastomose microartérielle, qui dépend de l'état des cellules endothéliales et influe sur le taux de thromboses artérielles. Dans $80 \%$ des cas de thrombose artérielle, on observe surtout les complications pendant les 72 heures suivant l'opération. La guérison de l'anastomose artérielle produit une hyperplasie de l'intima dont le principal type de cellules est le myofibroblaste. L'hyperplasie de l'intima a déjà été décrite comme un processus adaptatif qui se produit en réponse à un stress hémodynamique ou à des blessures au lit vasculaire. Pendant la guérison de la plaie, les fibroblastes prolifèrent, migrent et se différencient en myofibroblastes, dans un processus d'une durée de un à trois jours. Le mésylate d'imatinib (ST1571-Gleevec, Novartis, Allemagne) est un antagoniste des récepteurs du facteur de croissance dérivé des plaquettes, utile comme complément au sirolimus en cas de chirurgie cardiovasculaire pour soigner une resténose. Cependant, son utilité potentielle pour prévenir la thrombose artérielle en cas de chirurgie microvasculaire n'a pas été évaluée dans le cadre des chirurgies plastiques habituelles.
\end{abstract}

MÉTHODOLOGIE : Vingt-quatre lapins blancs mâles néo-zélandais choisis au hasard ont été divisés en six groupes ( $\mathrm{A}$ à $\mathrm{F}$ ), et les chercheurs ont retenu le modèle d'artère fémoral pour effectuer une anastomose artérielle. Après l'anastomose, les chercheurs ont administré une solution de tampon phosphate salin par voie orogastrique aux groupes $\mathrm{A}, \mathrm{B}$ et $\mathrm{C}$, et du mésylate d'imatinib aux groupes $\mathrm{D}, \mathrm{E}$ et $\mathrm{F}$ par sonde orogastrique deux fois par jour, à une dose de $10 \mathrm{mg} / \mathrm{kg}$, à compter de deux jours avant l'anastomose artérielle. Après l'anastomose, ils leur ont administré du mésylate d'imatinib pendant un, trois et sept jours, et ont consigné la régression de l'hyperplasie de l'intima.

RÉSULTATS : Dans les groupes à qui on avait administré du mésylate d'imatinib (c'est-à-dire les groupes D, E et F), la diminution de l'hyperplasie de l'intima a atteint jusqu'à $50 \%$, ce qui représentait une différence statistiquement significative. L'analyse histologique a confirmé une migration des cellules des muscles lisses de l'intima à la tunique moyenne les jours 3 et 7 dans les groupes $\mathrm{E}$ et $\mathrm{F}$.

CONCLUSION : La présente étude a révélé que le mésylate d'imatinib, amorcé comme prétraitement systémique prophylactique et maintenu pendant sept jours, réduisait graduellement l'hyperplasie de l'intima au foyer de l'anastomose.

icrovascular free flap transfer has emerged as a prominent techInique for the treatment of head and neck, breast, and upper and lower extremity deformities (1). It is an established and reliable technique in reconstructive surgery, with a reported success rate of $91 \%$ to $99 \%(2,3)$. One of the main reasons for failure, however, is the excessive pathological processes during the healing of microarterial anastomosis, which is dependent on the status of endothelial cells and affects the rate of arterial thrombosis. In $80 \%$ of arterial thrombosis cases, complications are primarily observed during the first $72 \mathrm{~h}$ after surgery. Denuded endothelium and exposed subendothelial tissues initiate extrinsic pathways of thrombosis at the anastomosis site (4-6). Exposure of subendothelial tissues to the bloodstream causes the formation of thrombotic plugs. Healing of arterial anastomosis results in neointimal hyperplasia, in which myofibroblasts comprise the predominant cell type. Neointimal hyperplasia is an early and essential step in the pathogenesis of atherosclerosis and restenosis. This step is characterized by extracellular matrix (ECM) degradation and medial vascular smooth muscle cell (SMC) migration to the intima and their proliferation. During wound healing, fibroblasts proliferate, migrate and differentiate into myofibroblasts - a process

${ }^{1}$ Sisli Etfal Research and Training Hospital Department of Plastic Surgery, Istanbul; ${ }^{2}$ Izmir Ataturk Research and Training Hospital Department of Plastic Surgery, Izmir; ${ }^{3}$ Abant Izzet Baysal University Hospital, Bolu; ${ }^{4}$ Sisli Etfal Research and Training Hospital Department of Anesthesia and Reanimation, Istanbul; ${ }^{5}$ Dokuz Eylul University Hospital Department of Pathology, Izmir, Turkey

Correspondence: Dr Kamuran Zeynep Sevim, Sisli Etfal Research and Training Hospital Department of Plastic Surgery, Acibadem Koftuncuoglu Street Is Bonkasi Bloklori A6 Blok d:33, Acibadem, Istanbul 34718, Turkey. Telephone 009-053-2520-3679, e-mail kzeynep.sevim@gmail.com 


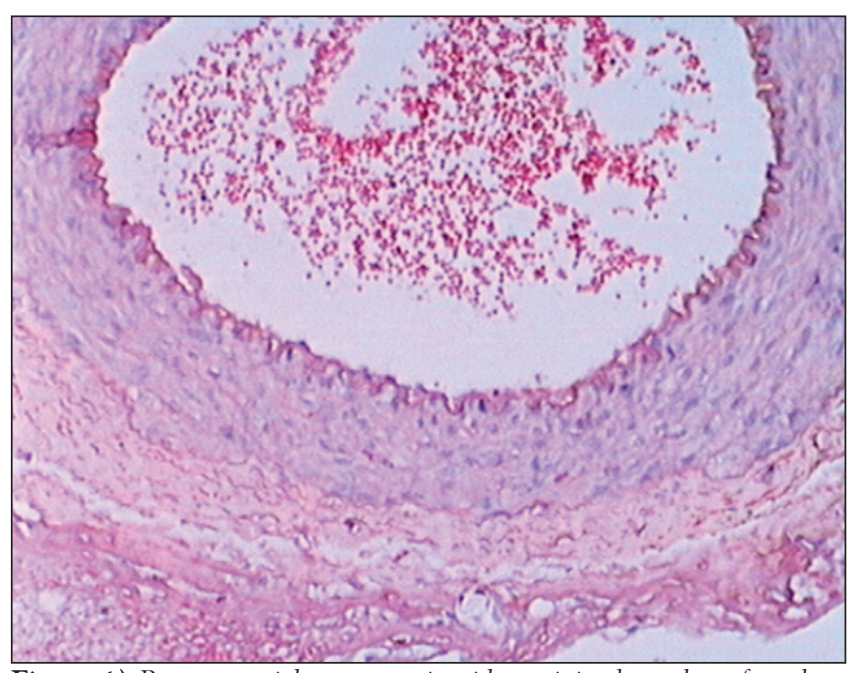

Figure 1) Patent arterial anastomosis with a minimal number of erythrocytes. Hematoxylin and eosin stain, original magnification $\times 40$

that takes one to three days. Following balloon-induced injury, myofibroblasts are detected at three days, reach a maximum level at seven to 14 days and often disappear by 28 days (7). The vascular endothelium regulates vasomotor tone and is essential in regulating blood flow in the microcirculation of the free flap. It is well known that meticulous dissection and precise surgical skill are important; however, even minute trauma to the vascular endothelium can provoke subendothelial injury and result in intimal hyperplasia of varying degrees. Intimal hyperplasia has been described previously as an adaptive process that occurs in response to hemodynamic stress or injuries to the vascular bed (8-11), and is believed to be an important contruibutor to the incidence of microvascular anastomosis occlusion. After injury occurs, vascular endothelial cells layer usually form a anticoagulant layer by secreting various mediators (eg, platelet-derived growth factor [PDGF], epidermal growth factor, basic fibroblast growth factor and transforming growth factor-beta) that facilitate blood flow $(12,13)$. The primary pathological mechanism involves platelet aggregation and degranulation with proliferation and, more importantly, migration of vascular SMCs, with an increase in matrix metalloproteinase concentration at the site of the endothelial injury. PDGF is considered to be the initiating factor of intimal hyperplasia (14). Imatinib mesylate (ST1571-Gleevec, Novartis, Germany) is a PDGF receptor blocker that targets three different activities (15-17). First, it blocks the tyrosine-kinase activation of abl/bcr-abl, which is a therapeutic strategy used in the treatment of chronic myeloid leukemia. Second, it blocks the tyrosine-kinase activity of c-kit, which is used as a therapeutic strategy in the treatment of gastrointestinal stromal tumours (18). Third, imatinib mesylate is a specific PDGF receptor blocker that aids in blocking the growth of SMCs $(3,19)$. Imatinib mesylate has found use as an adjunct to sirolimus in cardiovascular surgery for restenosis (20); however, its potential utility in arterial thrombosis in microvascular surgery has not been evaluated in routine plastic surgery practice. In our study, imatinib mesylate, which is a potent and specific tyrosine-kinase receptor blocker, was used in a rabbit model of femoral artery anastomosis. The potential inhibitory effects of this drug on intimal hyperplasia and SMC proliferation were investigated. Finally, we hypothesized that the oral administration of imatinib mesylate, initiated two days before planned arterial anastomosis, would significantly inhibit the intimal hyperplasia that leads to arterial thrombosis.

\section{METHODS}

The present study was a randomized, controlled experimental study initiated after obtaining local ethics committee approval from the
Izmir Ataturk Research and Training Hospital (Izmir, Turkey). Twenty-four male New Zealand white rabbits with a mean ( \pm SD) weight of $2650 \pm 100 \mathrm{~g}$ (range $2100 \mathrm{~g}$ to $3200 \mathrm{~g}$ ) were randomly selected to undergo the procedure. The femoral artery model was used for arterial anastomosis. The rabbit femoral artery model was chosen because the arterial wall structure of rabbits is anatomically analogous to human vessels. The animals were housed in separate cages at a constant mean room temperature of $21 \pm 3^{\circ} \mathrm{C}$ with $12 \mathrm{~h}$ light and $12 \mathrm{~h}$ dark cycles, and fed rabbit chow ad libitum. The experimental study consisted of 24 rabbits divided into six groups. In each group of animals, bilateral femoral artery anastomoses were performed; therefore, each group consisted of eight anastomoses. Groups A, B and C served as the control groups, and groups D, E and F were defined as the experimental groups. All of the interventions were conducted under $50 \mathrm{mg} / \mathrm{kg}$ ketamine (Ketalar, Pfizer, Turkey) and $50 \mathrm{mg} / \mathrm{kg}$ midazolam (Dormicum, Roche, Turkey) general anesthesia. The inguinal region of the rabbits was shaved and prepared with betadine solution. The posterior auricular veins were cannulized to provide the animals with additional analgesic throughout the course of the study. Bilaterally, femoral arteries were dissected and cut with a No.15 scalpel blade. After treating the vessels with topical heparin solution $(100 \mu \mathrm{g} / \mathrm{kg})$, the proximal and distal ends of the arteries were held with microclamps and an end-toend arterial anastomosis was formed with $9 / 0$ polypropylene sutures using meticulous technique. All interventions were performed by the same surgeon using a surgical microscope (OPMI Vario-S88, CarlZeiss Meditec, USA). Subsequently, a 'milking' test was performed to check the anastomosis, which was followed by skin closure. Following the anastomosis, to equalize the stress of orogastric intubation, control groups A, B and C received only phosphate-buffered saline (PBS) as vehicle. However, groups $\mathrm{D}, \mathrm{E}$ and $\mathrm{F}$ received imatinib mesylate via an orogastric tube at a dose of $10 \mathrm{mg} / \mathrm{kg}$ twice per day starting two days before the arterial anastomosis. The reviewer and the pathologist were blinded to the outcome measures. After performing the anastomosis, imatinib mesylate was continued at a dose of $10 \mathrm{mg} / \mathrm{kg}$ twice per day for one day postoperatively in group D; for three days postoperatively in group E; and for seven days postoperatively in group F. Therefore, group D received a total dose of $80 \mathrm{mg}$, group E received $160 \mathrm{mg}$ and group $\mathrm{F}$ received $320 \mathrm{mg}$ of imatinib mesylate over the course of the study. Arterial biopsies $1 \mathrm{~cm}$ in size were obtained from the anastomosis site on postoperative day 1 in groups $\mathrm{A}$ and $\mathrm{D}$; on day 3 in groups $\mathrm{B}$ and $\mathrm{E}$; and on day 7 in groups $\mathrm{C}$ and $\mathrm{F}$. The animals were euthanized with $50 \mathrm{mg} / \mathrm{kg}$ sodium thiopenthal (Pental, İE Ulugay, Turkey). The biopsy specimens were fixed in $10 \%$ buffered formaldehyde and paraffin blocks were prepared for histological assessment.

\section{Morhophometry}

Segmental sections $5 \mu \mathrm{m}$ thick were prepared and stained with hematoxylin and eosin, and Masson's trichrome and analyzed by the senior pathologist using a light microscope (Olympus BX-50, Olympus, Japan). The light microscope was connected to an image capture system and measurements were analyzed using digital image analysis software (JVC TK-890 E, Japan) (Image Tool, Uthscsa-Version 3.00 for Windows [Microsoft Corporation, USA], analysis 3 systems) (Figure 1). Intima and media thicknessess $(\mu \mathrm{m})$ were measured using a computer-assisted image analyzer system; the ratios of intima/media (index values) were subsequently calculated.

\section{Statistical analysis}

Statistical analysis of morphometric data was performed using factorial ANOVA and the Wilcoxon signed rank test, while MannWhitney $U$ tests were used for unpaired comparisons. The $\chi^{2}$ test was used to evaluate statistical differences in morphometric data between the imatinib mesylate and control groups. Statistical analysis of paired data (imatinib mesylate and control) were performed using the Wilcoxon signed rank test. Data are presented as mean \pm SEM, ' $\mathrm{n}$ ' indicates the number of animals and $\mathrm{P}<0.05$ was considered to be statistically significant. 
TABLE 1

Histomorphometric analysis

\begin{tabular}{|c|c|c|c|c|c|c|}
\hline & \multicolumn{6}{|c|}{ Group } \\
\hline & A & B & C & D & $\mathbf{E}$ & $\mathbf{F}$ \\
\hline Intima thickness, $\mu \mathrm{m}$ & $42.71 \pm 1.85$ & $55.82 \pm 3.62$ & $94.155 \pm 5.93^{*}$ & $71.62 \pm 3.31$ & $36.91 \pm 2.23^{*}$ & $24.72 \pm 2.32 *$ \\
\hline Media thickness, $\mu \mathrm{m}$ & $135.61 \pm 2.27$ & $132.81 \pm 6.4$ & $111.26 \pm 10.91$ & $121.21 \pm 10.02$ & $117.68 \pm 7.12$ & $111.95 \pm 9.06$ \\
\hline Intima/media ratio & $0.848 \pm 0.04$ & $0.482 \pm 0.03$ & $0.318 \pm 0.05^{\star}$ & $0.533 \pm 0.03$ & $0.367 \pm 0.01^{*}$ & $0.210 \pm 0.02 *$ \\
\hline
\end{tabular}

Data presented as mean \pm SEM. ${ }^{*} P<0.05$ compared with control

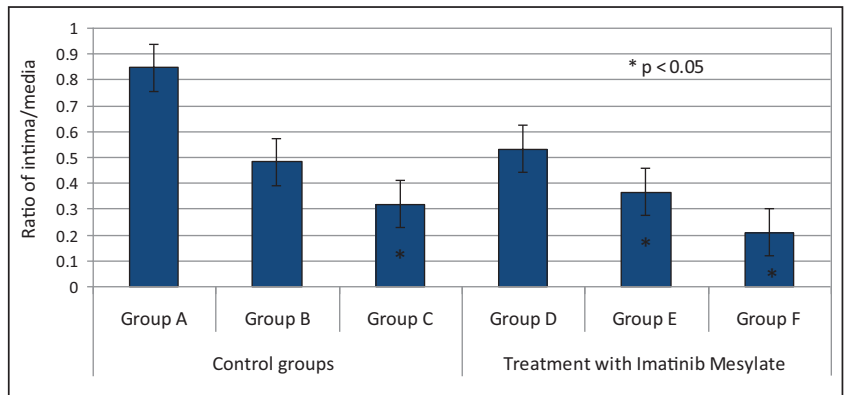

Figure 2) Bar graph comparing all groups with respect to intima/media thickness ratios

\section{RESULTS}

All of the animals survived the study. The arterial anastomosis sites were analyzed macroscopically by determining the number of thrombosed vessels, and microscopically in terms of the following: intimal thickness $(\mu \mathrm{m})$, tunica media thickness $(\mu \mathrm{m})$ and intima/media ratios (Table 1). Adverse effects of imatinib mesylate manifested as diarrhea in one rabbit due to systemic administration of imatinib mesylate. No other signs of adverse effects, such as delayed wound healing, overall abnormal behaviour or hair loss, were noted.

Macroscopically, arterial thrombosis was observed in one rabbit in group A, one rabbit in group B, four rabbits in group C, one rabbit in group $\mathrm{D}$, one rabbit in group $\mathrm{E}$ and two rabbits in group $\mathrm{F}$. Statistically significant differences were noted between groups $\mathrm{C}$ and $\mathrm{F}$, in which treatment group $\mathrm{F}$ received a total of $320 \mathrm{mg}$ of imatinib mesylate over the course of nine days. Statistical analysis revealed that among the control groups, intimal thickness increased incrementally and reached a peak value on postoperative day 7 (group C $0.94 \pm 5.93 \mu \mathrm{m}$ ), with intimal thickness less in groups B and C (group B 55.82 $\pm 3.62 \mu \mathrm{m}$; group A 42.71 $\pm 1.85 \mu \mathrm{m}$ ) (Table 1). The Kruskal-Wallis test revealed statistically significant differences among groups $\mathrm{A}, \mathrm{B}$ and $\mathrm{C}(\mathrm{P}<0.05)$ (Table 1, Figures 2 and 3).

In experimental groups $\mathrm{D}, \mathrm{E}$ and $\mathrm{F}$, which received imatinib mesylate for two days before performing the anastomosis, and one, three and seven days after the anastomosis, respectively, the results showed that intimal hyperplasia (measured in $\mu \mathrm{m}$ ) decreased by up to $50 \%$, which represented a statistically significant difference $(\mathrm{P}=0.0001$ [KruskalWallis test]). Intima/media thickness ratios were measured and statistically significant results were obtained among groups $\mathrm{D}, \mathrm{E}$ and $\mathrm{F}$ (group D 0.533 \pm 0.03 ; group E $0.367 \pm 0.01$; group F $0.210 \pm 0.02$; $\mathrm{P}=0.0001$ ). Histological analysis confirmed SMC migration from the tunica media to the tunica intima, especially on days 3 and 7 , in groups $\mathrm{E}$ and $\mathrm{F}$, which appeared as vacuolization in the tunica media and thinning of the vascular endothelium with a single layer of endothelial cells (Figures 4 and 5). Groups B and $\mathrm{C}$ demonstrated significant increases in the number of erythrocytes in the tunica media, which resembled injury and caused erythrocyte migration in elevated states of arterial thrombosis (Figure 7). To demonstrate the increase in fibrous tissue at the arterial anastomosis site, sections of the paraffin blocks were stained with Masson's trichrome. Dense SMC migration and an increased amount of connective tissue was noted particularly in the control groups. However, significant decreases in intimal hyperplasia

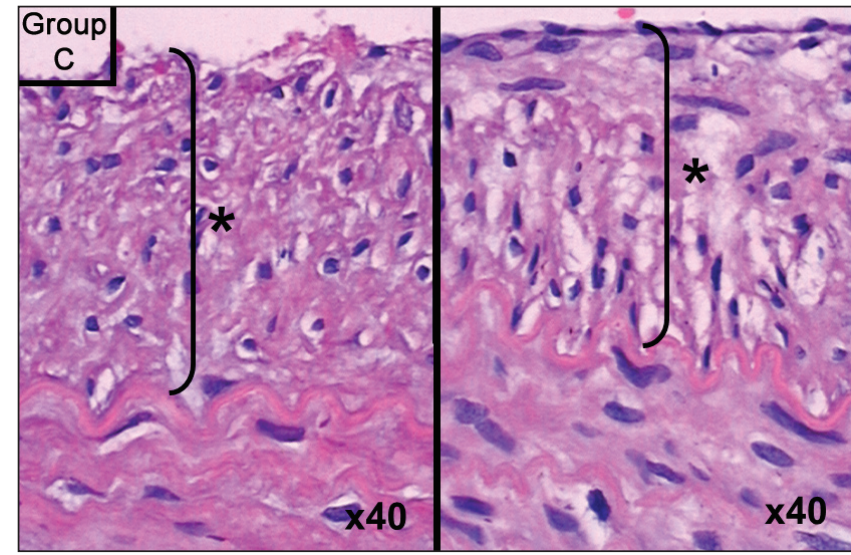

Figure 3) Group C slide showing intimal hyperplasia. Hematoxylin and eosin stain, original magnification $\times 40$. Asterisk (*) and bracket indicate thickness of intimal hyperplasia

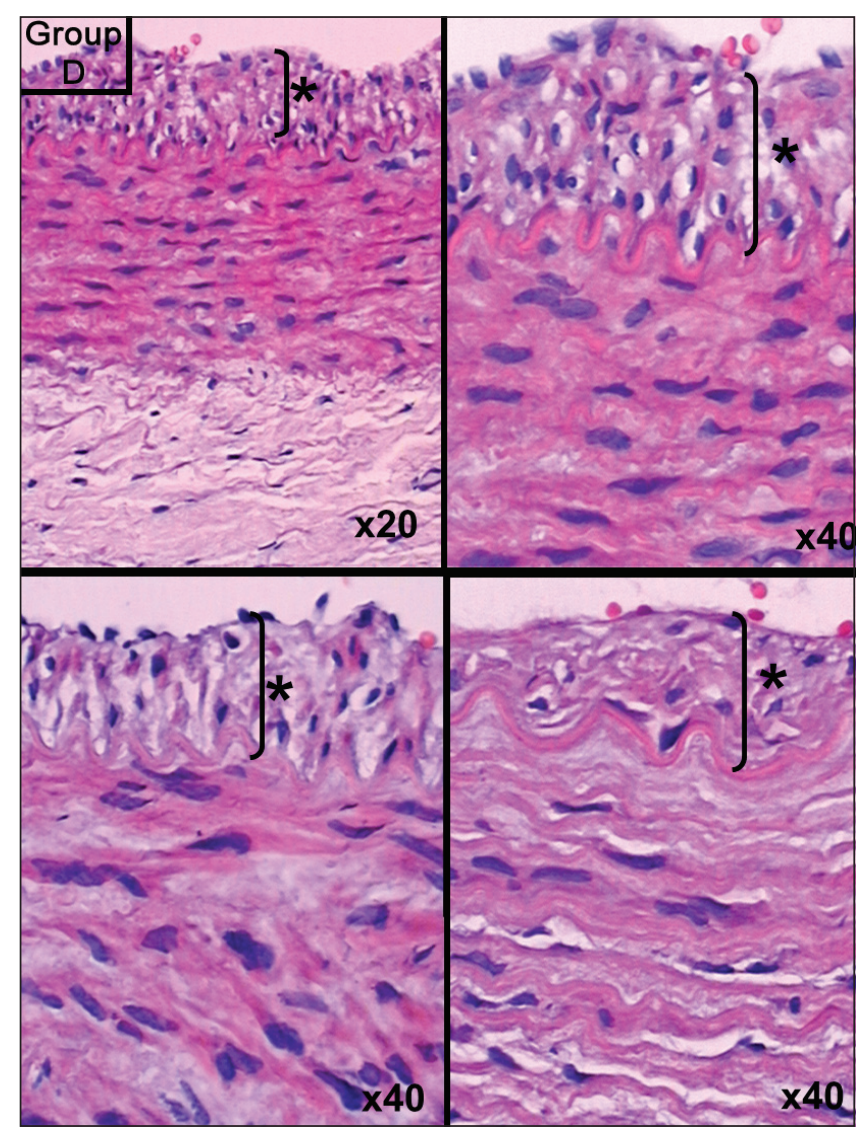

Figure 4) Group D slide showing intimal hyperplasia. Hematoxylin and eosin stain, original magnification indicated in lower right of each panel. Asterisk (*) and bracket indicate thickness of intimal hyperplasia 


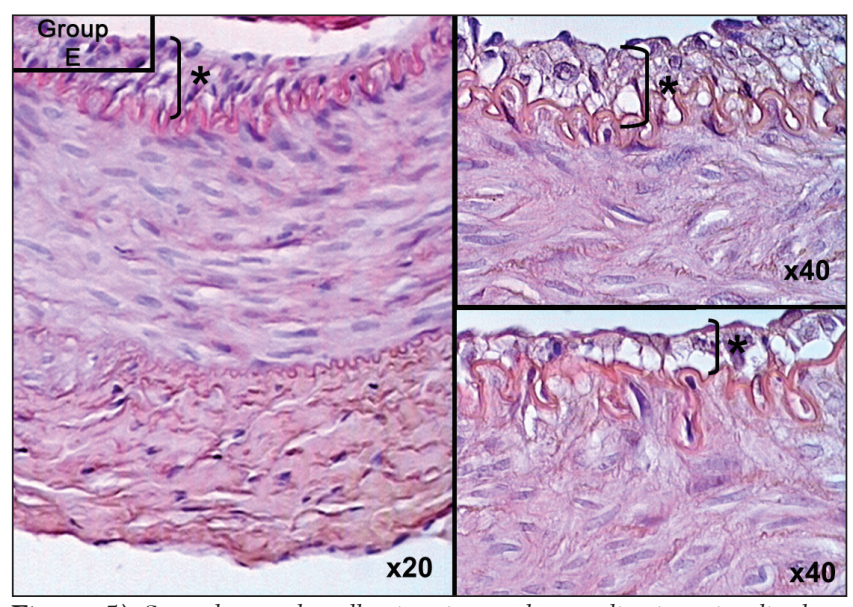

Figure 5) Smooth muscle cell migration and vacuolization visualized on postoperative day 3 of imatinib mesylate therapy. Hematoxylin and eosin stain, original magnification indicated at lower right of each panel. Asterisk (*) and bracket indicate thickness of intimal hyperplasia

and connective tissue were present in groups D, E and F (Figure 8). Anastomotic patency was also increased in groups D, E and F.

\section{DISCUSSION}

Regardless of the technical refinements in microsurgery, free tissue transfer procedures still possess a failure rate of 3\% to $5 \%$ due to occlusion of the anastomosis during the early and late postoperative periods (2). The etiology of flap loss can be separated into three categories:

1. Surgical technique (inaccurate dissection, inadequate anastomosis, false inset of flap or pedicle);

2. Reperfusion anomalies (ischemia time, spasm, hypovolemia, cold); and

3. Patient factors (environmental, systemic disease, infection) (5)

Kroll et al (3) aimed to determine the critical time period that a free flap should be monitored during the postoperative period and concluded that pedicle thrombosis occurred during the first $48 \mathrm{~h}$ in $50 \%$ of patients, with arterial thrombosis being the primary etiology (3). The major reason for failure is the problem of healing at the anastomosis line, especially in endothelial cells. Exposure of subendothelial tissues to the bloodstream induces the formation of a thrombotic plug. Vascular repair following endothelial injury is a complex process involving vascular inflammation, re-establishment of the luminal endothelial lining and SMC proliferation as well as progenitor cell recruitment. These processes are most active during the initial weeks after vascular injury, with the most prominent changes in messenger RNA expression levels observed shortly after injury in previous studies (21). This emphasizes the clinical importance of early therapeutic intervention to prevent excess intimal hyperplasia. Excess intimal hyperplasia is believed to be one of the contributory factors in the incidence of microarterial anastomosis occlusion $(21,22)$. The vascular endothelium comprises approximately $1 \%$ of the body mass of an adult and has a surface area of approximately $5000 \mu \mathrm{m}^{2}$. Such a large and potentially thrombogenic 'organ' secretes a number of products (4). If there is excess stasis or tunica media exposure, the thin sheet will include fibrous tissue and erythrocytes. Endothelialization occurs over the two weeks following anastomosis and, after eight weeks of remodelling, the vascular tissues revert into their previous form with a single layer of endothelium (23-25). Currently, the only available means for prevention of intimal hyperplasia is through inhibition of the mammalian target of rapamycin (mTOR) with the immunosuppressant rapamycin (26).

The purpose of the present study was to determine whether imatinib mesylate administered via an orogastric tube can inhibit the intimal hyperplasia that causes arterial occlusion over the subacute

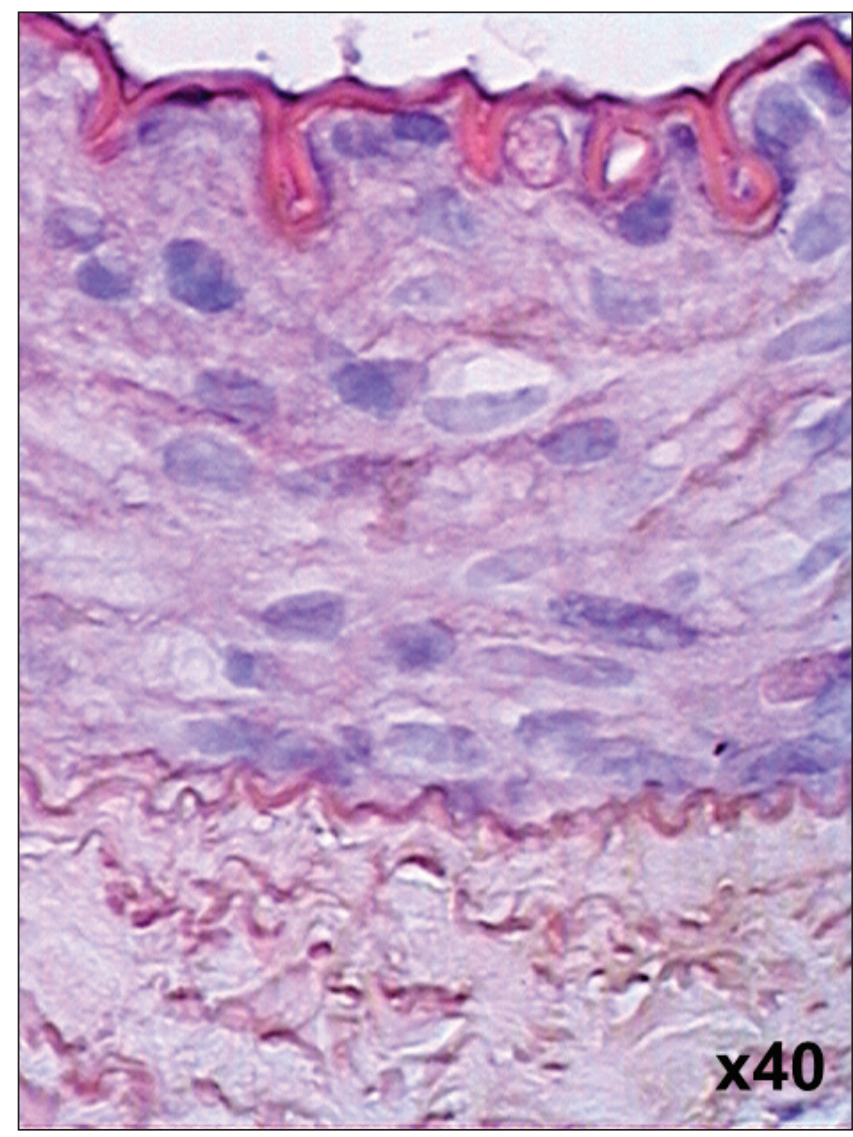

Figure 6) Thin layer of endothelium observed on postoperative day 7 after imatinib mesylate treatment. Hematoxylin and eosin stain, original magnification $\times 40$

postoperative period (three to seven days) after free flap surgery. Yang et al (11) ultrastructurally studied the intimal hyperplasia in healing microarterial anastomosis and concluded that myofibroblasts start forming after day three and their degree of differentiation increases over time and reaches a maximum at four weeks after the anastomosis (11). Vascular injury provokes the vascular endothelium to secrete many growth factors (eg, PDGF, epidermal growth factor, basic fibroblast growth factor), which in some circumstances results in intimal hyperplasia due to SMC migration from the tunica media to the tunica intima. Imatinib mesylate supresses three different tyrosine-kinase genes residing on chromosome 22 (13). When imatinib mesylate was first developed, it was used in the treatment of chronic myeloid leukemia patients by blocking bcrabl tyrosine-kinase and inducing apoptosis. The anticipated effects of imatinib mesylate on preventing arterial thrombosis and restenosis are hypothesized to result from blocking two other tyrosine kinases: the PDGF receptor kinase and c-kit receptor tyrosine-kinase (27-29). Recently conducted studies emphasized the critical role of PDGF on SMC proliferation and migration following vascular injury (30). Imatinib mesylate antagonizes the ligand-induced receptor activation of PDGF, which makes the drug especially ideal (31). A cost-effectiveness analysis was not performed in the present study; however, compared with other treatment modalities used to prevent intimal hyperplasia (eg, sirolimus, rapamycin), imatinib mesylate is quite cost effective (26). In our study, $400 \mathrm{mg}$ tablets of imatinib mesylate were dissolved in PBS and administered systemically. The beneficial effects of imatinib mesylate are observed at low concentrations $(1 \mu \mathrm{M}, 2 \mu \mathrm{M}$ and $3.7 \mu \mathrm{M})-$ approximately 100 times less concentrated than what is used in cancer treatment regimens (14). In the present study, we showed that relatively low doses of imatinib mesylate $(10 \mathrm{mg} / \mathrm{kg}$ twice per day) mitigate the deleterious side effects of the drug. SMC inhibition is known to occur at imatinib mesylate concentrations of $0.5 \mu \mathrm{M}$ to $10 \mu \mathrm{M}$. In the literature, 


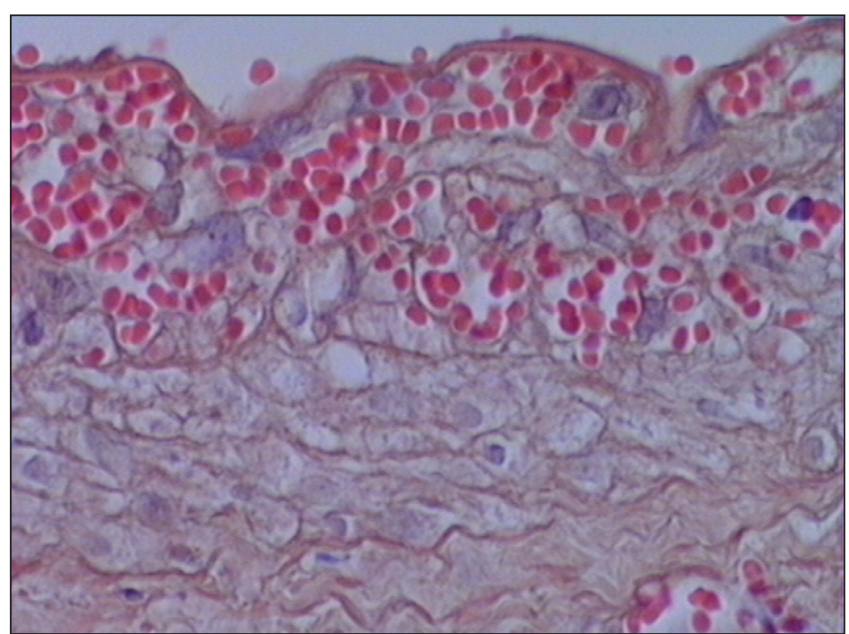

Figure 7) Erythrocytes in the tunica media of specimens from group $B$. Hematoxylin and eosin stain, original magnification $\times 40$

imatinib mesylate therapy has been used by cardiovascular surgeons to reduce neointimal hyperplasia due to balloon-induced injuries. Moreover, to obtain further insight into the effects of imatinib mesylate therapy on vascular anastomosis repair, gene expression in the vessel wall has been investigated (32). It was found that the expression of SMC cytoskeletal protein SM22-alpha is downregulated in damaged arteries when vascular SMCs assume a synthetic phenotype. However, in sirolimus and imatinib mesylate combination therapy groups, a strong upregulation of SM22-alpha expression was observed in the tunica media at day 4 after injury, suggesting that this treatment interferes with the phenotypic change of neointimal SMCs early after injury and inhibits intimal hyperplasia by maintaining SMCs in a more passive contractile phenotype.

In the present study, imatinib mesylate was initiated two days before performing the anastomosis so that a peak plasma concentration of the drug was present at the time of anastomosis. To determine the time frame in which imatinib mesylate was effective in preventing arterial thrombosis, the drug was administered up to seven days after the anastomosis to be consistent with similar cohort studies that have assessed similar time periods (28). In the present article, the short-term vasculoprotective effects of imatinib mesylate on arterial anastomosis and the potential use of PDGF antagonists in avoiding intimal hyperplasia are discussed. The results of the present study may be of importance when developing oral treatment strategies for prevention of arterial thrombosis due to pathological intimal hyperplasia. Histomorphometrically, the imatinib mesylate groups began to show a significant decrease in the amount of SMC migration to the tunica intima from postoperative day 3 until postoperative day 7. A literature review (30) reported that vein graft restenosis was prevented up to 14 days postoperatively and that 28 days after anastomosis, imatinib mesylate had no effect on arterial anastomosis and intimal hyperplasia. Therefore, we conclude that imatinib mesylate exhibits vasculoprotective properties during the early stages of arterial thrombosis. Several other vasculoprotective agents, such as somatostatin analogues and sirolimus, have been used and studied; however, imatinib mesylate showed comparable results with fewer side effects (20). Side effects, including nausea, vomiting and cytopenia, may be overcome by the development of local forms of imatinib mesylate. The imatinib mesylate groups in our study demonstrated a $50 \%$ decrease in intimal thickening and showed histological decreases in SMC migration. Imatinib mesylate has been approved by the United States Food and Drug Administration in many treatment protocols for diseases such as pulmonary hypertension, systemic sclerosis, atherosclerosis, dermatofibrosarcoma protuberans and even large vessel vasculitis (33-35). Healing of arterial anastomosis results in intimal hyperplasia in which myofibroblasts comprise the predominant cell type. During wound healing, fibroblasts proliferate, migrate and

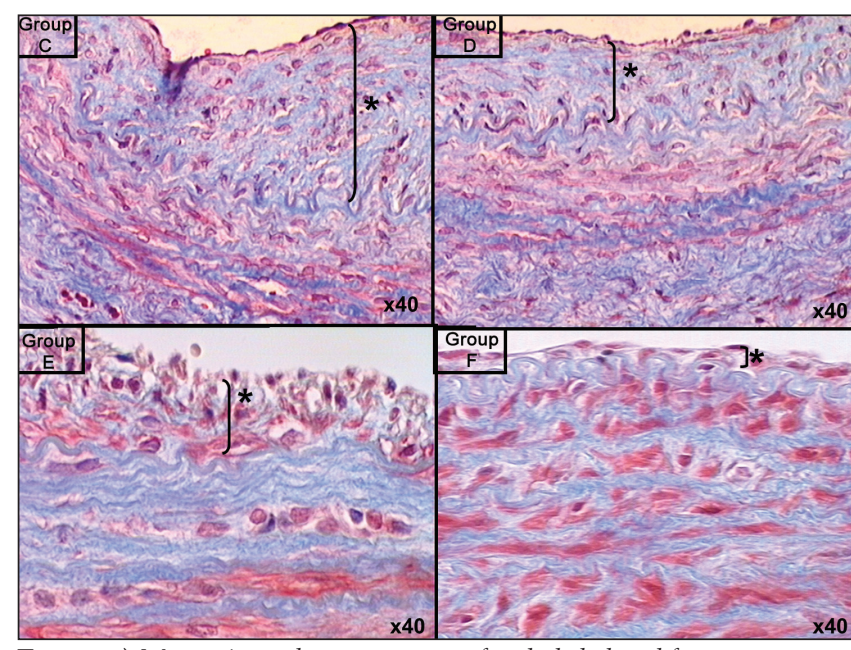

Figure 8) Masson's trichrome staining of endothelial proliferation in specimens from groups D, E and F compared with the control group C. Original magnification $\times 40$. Asterisk (*) and bracket indicate thickness of intimal hyperplasia

differentiate into myofibroblasts - a process that takes one to three days. Following balloon-induced injury, myofibroblasts have been detected at three days, reach a maximum level at seven to 14 days and often disappear by 28 days (7). This finding formed the central thesis of our study and we believe that imatinib mesylate is a promising therapeutic drug for preventing subacute thrombosis stemming from intimal hyperplasia. The effectiveness of the drug should be investigated in future studies of venous thrombosis.

\section{Study limitations}

Ideally, arterial patency could have been more quantitatively demonstrated by laser Doppler flowmetry or pletysmography rather than the 'milking' test that was performed following anastomosis in the present study. However, the data collected are nevertheless useful to show that in subacutely formed arterial thrombosis situations, imatinib mesylate can prevent intimal hyperplasia by up to $50 \%$. Furthermore, our study did not contain groups with sufficiently long follow-up periods to determine whether the myofibroblasts and intimal hyperplasia eventually decrease and disappear, but the literature suggests that this would probably be the next step.

\section{CONCLUSION}

In free flap surgery, the first 14 days are vital in the survival of the arterial anastomosis and, thus, the flap. When thrombosis is detected, surgical re-exploration or medical therapy must be initiated without delay. Reducing intimal hyperplasia has a critical role in preventing arterial thrombosis and PDGF tyrosine-kinase inhibitors play a significant role in preventing intimal hyperplasia. Our study revealed that imatinib mesylate, which was initiated as a systemic pretreatment and continued for seven days, gradually decreased intimal hyperplasia at the anastomosis site. Seven days after arterial anastomosis, the intima/ media thickness ratio decreased by up to $50 \%$ in a rabbit model, with minimal diarrhea as the only side effect.

\section{REFERENCES}

1. Schusterman MA, Miller MJ, Reece JP, et al. A single center's experience with 308 free flaps for repair of head and neck cancer defects. Plast Reconstr Surg 1994;93:472-8.

2. Hallock GG. Impact of the successful flap but failed reconstruction. J Rec Microsurg 2000;16:589-92.

3. Acland RD, Trachtenberg L. The histopathology of small arteries following experimental microvascular anatomosis. Plast Reconstr Surg 1977;60:868-71.

4. Kroll SS, Schusterman MA, Reece GP, et al. Timing of pedicle thrombosis and flap loss after free tissue transfer. Plast Reconstr Surg $1996 ; 98: 1230-3$ 
5. Topalan M, Arıncı A, Olgac V, et al. Effect of distant specific foci on the patency. J Rec Microsurg 2000;16:297-301.

6. Clowes A, Reidy M, Clowes M. Mechanism of stenosis after arterial injury. Lab Invest 1983;49:208-15.

7. Scott NA, Cipolla GD, Ross CE, et al. Identification of a potential role for the adventitia in vascular lesion formation after balloon over stretch injury of porcine coronary arteries. Circulation 1996;93:2178-87.

8. Lidman D, Daniel RK. The normal healing process of microvascular anastomoses. Scand J Plast Reconstr Surg 1981;15:103-10.

9. Göncü T, Yavuz Ş, Çekirdekçi A, Karaca I. The effect of Perindopril on intimal hyperplasia forming after vascular injury. Turk J Cardiothorac Surgeons 2001;9:109-14.

10. O’Malley MK. Intimal hyperplasia. Eur J Vasc Surg 1992;6:343-5.

11. Yang JP, Glickman AM, Edwards V, et al. An ultrastructural study of the intimal hyperplasia in healing microarterial anastomoses. Microsurgery 1998;18:391-6.

12. Lauritzen C, Hansson HA. Microvascular repair after the sleeve anastomosis. An ultrastructural study in the rat femoral vessel. Scand J Plast Reconstr Surg 1980;14:65-70.

13. Crowley ST, Ray CJ, Nawaz D, Majack RA, Horwitz LD. Multiple growth factors are released from mechanically injured vascular smoothmuscle cells. Am J Physiol 1995;269:H1641-7.

14. Ross R, Raines EW, Bowen-Pope DF. The biology of plateletderived growth factor. Cell 1986;46:155-69.

15. Savage DG, Antmann KH. Imatinib mesylate - a new oral targeted therapy. N Eng J Med 2002;346:683-93.

16. Myllarniemi M, Frosen J, Ramirez L, Buchdunger E, Lemstrom K, Hayry P. Selective tyrosine kinase inhibitor for the platelet-derived growth factor receptor in vitro inhibits smooth muscle cell proliferation after reinjury of arterial intima in vivo. Cardiovasc Drugs Therapy 1999;13:159-68.

17. Leppanen O, Rutanen J, Hiltunen M, et al. Oral imatinib mesylate (STI571) improves the efficacy of local intravascular endothelial growth factor-C gene transfer in reducing neointimal growth in hypercholesterolemic rabbits. Circulation 2004;109:1140-6.

18. Druker BJ, Talpaz M, Hresta DJ, et al. Efficacy and safety of a specific inhibitor of the bcr-abl tyrosine kinase in chronic myeloid leukemia. N Eng J Med 2001;344:1031-7.

19. Frate JL, Tallman MS, Variakojis D, et al. Chronic myeloid leukemia following therapy with imatinib mesylate (Gleevec) bone marrow histopathology and correlation with genetic status. Am J Clin Pathol 2003;119:833-41.

20. Tigerstedt NM, Aavik E, Lehti S, Hayry P, Savolainen-Peltonen H. Mechanisms behind the synergistic effect of sirolimus and imatinib in preventing restenosis after intimal injury. J Vasc Res 2009; $46: 240-52$.
21. Guzeloglu M, Reel B, Atmaca S, Bagriyanik A, Hazan E. The effects of PPAR gamma agonist rosiglitazone on neo-intimal hyperplasia in the rabbit carotid anastomosis model. J Cardiothorac Surg 2012;7:57.

22. Salgado CJ. Effects of late loss of arterial inflow on free flap survival. J Rec Microsurg 2002;18:579-84.

23. Khouri RK, Cooley BC, Kevna DM, et al. Thrombosis of microvascular anastomosis. Plast Reconstr Surg 1990;86:110-7.

24. Guzeloglu M, Gul M, Reel B, Yurekli I, Aykut K, Hazan E. The effects of zoledronic acid on neointimal hyperplasia: A rabbit carotid anastomosis model Anadolu Kardiyol Derg 2011;11:93-100.

25. Libby P, Schwartz D, Brogi E, Tanaka H, Clinton SK. A cascade model for restenosis. A special case of atherosclerosis progression. Circulation 1992;86:III47-52.

26. Mills B, Robb T, larson DF. Intimal hyperplasia: Slow but deadly. Perfusion 2012; DOI:10.1177/02670659112452316 (E-pub ahead of print).

27. Esclamado RM, Carroll WR. The pathogenesis of vascular thrombosis and its impact in microvascular surgery. Head Neck 1999;21:355-62.

28. Vallieres K, Petitclerc E, Laroche G. On the ability of imatinib mesylate to inhibit smooth muscle cell proliferation without delaying endothelialization: An in vitro study. Vascular Pharmacology 2009;51:50-6.

29. Clowes AW, Schwartz SM. Significance of quiescent smooth muscle cell migration in the injured rat carotid artery. Circ Res 1985;59:139-45.

30. Makiyama Y, Toba K, Kato K, et al. Imatinib mesylate inhibits neointimal hyperplasia via growth inhibition of vascular smooth muscle cells in a rat model of balloon injury. Tohoku J Exp Med 2008;215:299-306.

31. Carroll M, Ohno-Jones S, Tamura S et al. CGP 57148, a tyrosine kinase inhibitor inhibits the growth of cells expressing bcr-abl, tel-abl and tel-PDGFR fusion proteins. Blood 1997;90:4947-52.

32. Shanahan CM, Weissberg PL, Metcalfe JC. Isolation of gene markers of differentiated and proliferating vascular smooth muscle cells. Circ Res 1993;73:193-204.

33. Wang CH, Anderson N, Li SH, et al. Stem cell factor deficiency is vasculoprotective: Unraveling a new therapeutic potential of imatinib mesylate. Circ Res 2006;99:617-25.

34. Zhu JH, Li QW, Xiao WH, Sun JZ, Wang RL, Lu JY. Advanced dermatofibrosarcoma protuberans treated with imatinib mesylate. Zhonghua Zhong Liu Za Zhi 2011;33:470-7.

35. Sata M, Saiura A, Kunisato A, et al. Hematopoietic stem cells differentiate into vascular cells that participate in the pathogenesis of atherosclerosis. Nat Med 2002;8:403-9. 